\title{
Characterization of SdGA, a cold-adapted glucoamylase from Saccharophagus degradans
}

Natael M. Wayllace, Nicolas Hedín, María V. Busi* and Diego F. Gomez-Casati*

Centro de Estudios Fotosintéticos y Bioquímicos (CEFOBI-CONICET) - Universidad Nacional de Rosario, Suipacha 531, 2000 Rosario, Argentina

* Authors for correspondence:

busi@cefobi-conicet.gov.ar

gomezcasati@cefobi-conicet.gov.ar 


\begin{abstract}
We investigated the structural and functional properties of SdGA, a glucoamylase (GA) from Saccharophagus degradans, a marine bacterium which degrades different complex polysaccharides at high rate. SdGA is composed mainly by a N-terminal GH15_N domain linked to a C-terminal catalytic domain (CD) found in the GH15 family of glycosylhydrolases with an overall structure similar to other bacterial GAs. The protein was expressed in Escherichia coli cells, purified and its biochemical properties were investigated. Although SdGA has a maximum activity at $39^{\circ} \mathrm{C}$ and $\mathrm{pH} 6.0$, it also shows high activity in a wide range, from low to mild temperatures, like cold-adapted enzymes. Furthermore, SdGA has a higher content of flexible residues and a larger CD due to various amino acid insertions compared to other thermostable GAs. We propose that this novel SdGA, is a cold-adapted enzyme that might be suitable for use in different industrial processes that require enzymes which act at low or medium temperatures.
\end{abstract}

Keywords: glucoamylase, Saccharophagus degradans, marine bacteria, cold-adapted, bioethanol. 


\section{Introduction}

Glucoamylases (GAs) are hydrolytic enzymes also known as amyloglucosidases, glucan 1,4-alphaglucosidases or exo-1,4- $\alpha$-glucosidases, EC 3.2.1.3. GAs hydrolyze glycosidic $\alpha-1,4$ bonds (but also $\alpha$ 1,6 bonds) from the non-reducing ends of starch molecules and maltooligosaccharides releasing $\beta$-Dglucose. These are typically microbial enzymes present in archaea, bacteria and fungi but absent in animals and plants, and they are classified into the GH15 family of glycoside hydrolases (www.cazy.org) [1, 2].

Glucoamylases from the GH15 family are multi-domain enzymes characterized by having a catalytic domain $(\mathrm{CD})$ with a barrel-shaped $(\alpha / \alpha)_{6}$, sometimes bound to a non-CD [1]. Depending on its origin, this non-CD could be a carbohydrate binding module (CBM) from CBM20 or CBM21 families (found, for example, in the GAs from Aspergillus niger or Rhyzopus oryzae, respectively) [3, 4]. However, there are other GA proteins that lack associated modules (such as that from Sacharomycopsis fibuligera) or have a particular N-terminal domain enriched in serine or threonine residues such as the GA from Saccharomyces cerevisiae [1]. Finally, most prokaryotic GAs contain the characteristic $(\alpha / \alpha)_{6}$ barrel CD with a N-terminal $\beta$-sandwich domain such as the enzyme from Thermoanaerobacterium thermosaccharolyticum [5].

The main application of GAs (sometimes together with $\alpha$-amylases and pullulanases) occurs in the process of saccharification of partially processed starch or dextrins to obtain glucose. Starch is the source

of reserve carbohydrates in plant cells and algae and is one of the main renewable resources in nature [69] and it is composed by glucose molecules linked through a glycosidic bond. Starch consists mainly of two homopolysaccharides: amylopectin and amylose. Amylopectin is a polymer of D-glucose linked by $\alpha-1,4$ bonds with about $5 \%$ branching with $\alpha-1,6$ bonds, whereas amylose is essentially a linear polymer of glucose linked by $\alpha-1,4$ glycosidic bonds with a small number of ramifications [7]. Starch is also a major component of most of the world's staple foods such as rice, corn, potatoes, beans, wheat and cassava. In order to be used in the human diet, starch is frequently subjected to both chemical and enzymatic transformations to produce a wide variety of products, such as starch hydrolysates, glucose syrups, fructose, maltodextrin derivatives or cyclodextrins, which are used largely in the food industry [10]. In addition, starch is also widely used in other industries such as for the production of many textiles, pharmaceuticals, biodegradable plastic industry and in the production of biofuels, mainly bioethanol [11].

Over several years, many GA overproducing strains have been isolated in order to obtain high quantities of the enzyme. However, a more targeted strategy at the present is the cloning of specific genes or the discovery of new enzymes and their overexpression in heterologous organisms [10]. In the last 
decades, GAs from hyperthermophilous archaea of the genus Sulfolobus, Thermoplasma, Picrophilus and Methanoccocus have been investigated and characterized, and showed a very high thermostability and optimum temperature but a low specific activity [12-14]. In contrast, most of the GAs from fungi have optimal activity at $45^{\circ} \mathrm{C}$ and low $\mathrm{pH}[10,15,16]$. Some fungal glucoamylases such as those from Aspergillus strains are widely used in industrial processes for starch hydrolysis because they display high activity at temperatures between 45 and $60^{\circ} \mathrm{C}[10]$.

Currently, there is strong interest in finding GAs with a better performance at low temperatures because these enzymes would avoid the heating requirement in some industrial processes such as starch saccharification among others, and, in this way, production costs could be minimized [17].

Recently, many amylases from marine bacteria have been characterized and proposed as a good alternative for starch degradation [18-21]. Saccharophagus degradans is a gram-negative bacterium that was isolated from a marsh grass, Spartina alterniflora, found at the bottom of the Chesapeake Bay, MD, USA [22]. S. degradans is able to degrade at least ten complex polymers such as agar, alginate, chitin, cellulose, fucoidan, laminarin, pectin, pullulan, starch and xylan [22]. These polymers are derived from numerous sources, such as algae, land plants, crustaceans, bacteria, and fungi. The high degradation rate of the different polysaccharides shown by S. degradans makes this bacterium a good candidate to obtain and characterize the properties of the enzymes that degrade these polymers.

In this way, we decided to carry out the structural and functional characterization of a putative GA from $S$. degradans (SdGA). The ability of SdGA to catalyze the reaction at low and medium temperatures, as well as its low thermal stability and increased amino acid flexibility compared to other more thermostable GAs, allow it to be classified as a cold-adapted enzyme. We propose that SdGA constitutes a good alternative for different industrial processes such as starch saccharification at low or mild temperatures and its subsequent application in biofuel production, mainly bioethanol.

\section{Materials and Methods}

\subsection{Construction of the recombinant expression vector and transformation of $E$. coli cells}

The cDNA sequence coding for the mature form of the GA from S. degradans (ABD79864.1), named $S d G A$, was synthesized and cloned into the pRSF-DUET vector by Genscript Biotech Corp. 
(Piscataway, NJ, USA) and the construction was named pRSF-DUET_SdGA.SdGA was synthesized with codon optimization for heterologous expression in E. coli cells (GenBank MT754655) and was fused to a 5' sequence coding for a His 6 tag at the N-terminal region of the SdGA protein.

\subsection{Expression and purification of SdGA}

E. coli BL21(DE3) Rosetta was transformed with pRSF-DUET_SdGA and colonies were selected in LB agar plates containing $25 \mathrm{mg} / \mathrm{ml}$ of kanamycin and $50 \mathrm{mg} / \mathrm{ml}$ of chloramphenicol. Transformed cells were cultured in LB media containing the same antibiotics at $37^{\circ} \mathrm{C}$ to $A 600 \sim 0.5-0.6$. Protein expression was induced at $37^{\circ} \mathrm{C}$ with isopropyl- $\beta$-D-thiogalactopyranoside (IPTG) at a final concentration of $1 \mathrm{mM}$ for $2 \mathrm{~h}$. The cells were harvested by centrifugation at 5,000 rpm for $10 \mathrm{~min}$, , resuspended in 20 $\mathrm{mM}$ sodium phosphate buffer $(\mathrm{pH} 7.0)$ at $4^{\circ} \mathrm{C}$ and then disrupted with an ultrasonicator (VCX130, Sonics and Materials Inc., Newtown, CT, USA). The homogenate was centrifuged at 5,000 rpm for $20 \mathrm{~min}$. Recombinant His-tagged-SdGA was purified from the soluble fraction using a HiTrap Chelating column (HiTrapTM Chelating HP, Amersham Biosciences) equilibrated with $0.1 \mathrm{M} \mathrm{NiSO}_{4}$. The protein was eluted using a discontinuous gradient of increasing imidazole concentration (20 to $500 \mathrm{mM}$ ). The purified enzyme was concentrated and stored at $-20^{\circ} \mathrm{C}$ and was found to be stable for at least 2 months.

\subsection{Sequence analysis, flexibility evaluation and homology modeling of SdGA}

Similarity search of SdGA was performed using the BLASTp algorithm at the National Center for Biotechnology Information (NCBI) database (https://blast.ncbi.nlm.nih.gov/Blast.cgi). Computer-assisted protein sequence analyses were performed using ClustalW version 2.0. [23]. The phylogenetic tree for SdGA was constructed using maximum likelihood method based on the JTT matrix-based model with Bootstrap method phylogeny test and 500 replications using MEGA7 program [24, 25].

The amino acid sequence of SdGA and other GAs were analyzed and compared using PSSM-based encoding method from FlexPred server (http://flexpred.rit.albany.edu) to evaluate the flexibility or rigidity of the residues in the $\mathrm{CD}[26]$. The percentage of glycine $(\% \mathrm{G})$ and flexible residues $(\% \mathrm{~F})$ within the $\mathrm{CD}$ were calculated.

3D structural model was obtained using the Modeller @TOME V3 program [27] using T.I.T.O. (Tool for Incremental Threading Optimization) for the alignment between query and template [27]. The 3D model of SdGA was built using the structure of a GA from Thermoanaerobacterium thermosaccharolyticum as a template (PDB entry: 1LF6, 34\% identity). The quality of the model was 
evaluated with ProSA-web structure analysis program [28, 29] and Verify 3D [30]. Superposition of SdGA/tGA was performed using PyMOL software (The PyMOL Molecular Graphics System, Version 2.0 Schrödinger, LLC, https://pymol.org/2/).

\subsection{Glucoamylase activity assay and kinetic analysis}

Glucoamylase activity was measured by determining free glucose released after maltose hydrolysis. The reaction mixture consisted of $0.1 \mathrm{M}$ sodium phosphate buffer ( $\mathrm{pH}$ 6.0) containing $2 \%$ (w/v) maltose, $0.032 \mu \mathrm{g} / \mu \mathrm{l}$ of SdGA at final volume $100 \mu \mathrm{l}$ at $39^{\circ} \mathrm{C}$ for $20 \mathrm{~min}$. The amount of released glucose was determined using a commercial kit based on the method of glucose oxidase (GOD)/peroxidase (POD) (Wiener laboratories, Rosario, SF, Argentina) [31]. One unit of GA hydrolytic activity was defined as the amount of enzyme needed to release $1 \mu \mathrm{mol}$ of glucose per min. at $39^{\circ} \mathrm{C}$. Assays were performed at least by triplicate at different enzyme concentrations to ensure steady-state conditions. Protein concentrations were estimated according to the method of Bradford [32].

The effect of maltose concentration on SdGA activity was evaluated in $0.1 \mathrm{M}$ sodium phosphate buffer ( $\mathrm{pH} 6.0$ ) at $39^{\circ} \mathrm{C}$. The kinetic parameters $K_{m}, k_{\text {cat }}, S_{0.5}, V_{\max }$ and $n_{\mathrm{H}}$ were calculated with a computer program using the Levenberg-Marquardt algorithm for regression by fitting the data to the Hill equation [33]. $S_{0.5}$ is defined as the concentrations of substrate that give $50 \%$ maximal activity $\left(V_{\max }\right), k_{\mathrm{cat}}$ is the turnover number and $n_{\mathrm{H}}$ is the Hill number.

The effect of $\mathrm{pH}$ on the activity of SdGA was determined in two $0.1 \mathrm{M}$ buffers with maltose as the enzyme substrate (sodium acetate buffer, $\mathrm{pH} 4$ - 5.6 and sodium phosphate buffer, $\mathrm{pH} 6$ - 8.0, respectively) at $39^{\circ} \mathrm{C}$. The effect of temperature on SdGA activity was determined with $2 \%(\mathrm{w} / \mathrm{v})$ maltose between $10-$ $50^{\circ} \mathrm{C}$ as described above. Temperature stability assays were performed by incubating the same quantity of SdGA at different temperatures for 0 to $30 \mathrm{~min}$., and the residual activity was measured under standard assay conditions. The effect of metabolites on the thermal stability of SdGA was measured using $0.1 \mathrm{mM}$ acarbose (Sigma-Aldrich cat. $\left.\mathrm{n}^{\circ} 56180-94-0\right), 1 \mathrm{mM} \mathrm{CaCl}_{2}$ or $10 \%(\mathrm{v} / \mathrm{v})$ glycerol. The first order equation $\ln \left(\mathrm{A} / \mathrm{A}_{0}\right)=-k$. $\mathrm{t}$ was used to calculate the inactivation rate constant $\left(k, \min ^{-1}\right)$. $\mathrm{A}$ is the residual activity at time $\mathrm{t}$ and $\mathrm{A}_{0}$ is the initial activity at time zero. $D$-value (Decimal reduction time), the time to reduce the initial activity $90 \%$, was calculated from the equation: $D=\ln (10) / k$ as described [34]. All measurements were made at least by triplicate. Significant differences were determined by one-way ANOVA and Dunnet test using GraphPad Prism version 5.0 software (GraphPad Software, La Jolla, CA, USA) 


\subsection{Additional methods}

The purified SdGA was analyzed by SDS-PAGE using 12\% (w/v) gels as described by Laemmli [35] with a Bio-Rad Mini Protean system (Bio-Rad, Hercules CA, USA). Gels were stained by Coomassie

Blue and/or electro-blotted onto nitrocellulose membranes (HybondTM-ECLTM, Amersham Biosciences, UK). Electroblotted membranes were incubated with penta-His antibody (Qiagen, Valencia, CA, USA). The antigen-antibody complex was visualized with alkaline phosphatase-linked to anti-rabbit IgG followed by staining with 5-bromo-4-chloroindol-2-yl phosphate and nitro blue tetrazolium [36].

\section{Results}

\subsection{Sequence analysis and domain identification}

The analysis of the nucleotide sequence of SdGA shows the presence of an open reading frame of 2,409 bp coding for a putative GH15 GA. The protein is composed by 803 amino acids with a calculated molecular mass of $87.4 \mathrm{kDa}$. The analysis using SignalP-5.0 Server (http://www.cbs.dtu.dk/services/SignalP/) revealed the presence of a 20 amino acids signal peptide (SP) in the N-terminus of SdGA. Using InterPro v.79.0 server (http://www.ebi.ac.uk/interpro/) we found that SdGA contains a family 15 glycoside hydrolase N-terminal domain (GH15_N, amino acids 38-322), uniquely found in bacterial and archaeal glucoamylases and glucodextranases, and a C-terminal GH15like CD (GH15L-CD, amino acids 340-781) similar to the six-hairpin domain present also in the GH15 family (Figure 1a). The CD contains six $\alpha$-hairpins arranged in a closed circular array named $\alpha / \alpha$ toroid fold, [37]. Both domains are connected by a linker region (LR) composed by two $\alpha$-helices, according to the analysis with Jpred 4 (http://www.compbio.dundee.ac.uk/jpred/) [38].

The amino acid sequence of SdGA displayed the highest sequence identity with marine GAs from Gilvimarinus polysaccharolyticus (WP_049722861.1, 67\% identity), and Gilvimarinus agarilyticus (WP_041522105.1, 66\% identity). Figure 1b showed a multiple sequence alignment of the CDs of SdGA and several other known bacterial and fungal GAs. We found that SdGA contained five conserved regions (S1 to S5, boxed in Figure 1b) typically found in the CD of GAs defined previously [39]. In addition, SdGA contains two conserved glutamate residues, E513 and E745 (marked with red arrows, Figure 1b), 
that are the putative catalytic acid and base, which correspond to the E438 and E636 residues in $T$. thermosaccharolyticum GA [5].

Based on the amino acid sequence of SdGA, we have constructed a phylogenetic tree using the maximum likelihood method. Clearly, SdGA showed phylogenetic similarity with other GAs from marine bacteria but switched to different clusters away from other non-marine bacterial species, such as Clostridium sp. and also fungi and archaea, indicating the divergence of GAs among organisms (Figure 2).

\subsection{Homology modelling of SdGA}

A homology model of SdGA protein was built as described under Materials and Methods section using the 3D structure of tGA, a GA from Thermoanaerobacterium thermosaccharolyticum (PDB entry: 1LF6, 34\% identity). Analysis using Verify 3D program showed that $81.6 \%$ of the residues have averaged 3D-1D score higher than 0.2, whereas a Z-score of -7.05 was obtained using ProSA-web. According to these results, we found that the SdGA model has a good quality.

The SdGA model exhibited a fold similar to tGA with both $\alpha$-helical and $\beta$-sheet secondary structures conserved (Figure 3a). Three structurally different regions can be distinguished, (i) the Nterminal domain, which is made up of 16 antiparallel $\beta$-strand segments divided into $2 \beta$-sheets; (ii) the 2 $\alpha$-helice linker region and (iii) the C-terminal domain, which has, as described above, an $(\alpha / \alpha)_{6}$ barrel structure similar to other GAs (Figure 3a).

The superimposition of the polypeptide backbone structures of SdGA and tGA showed that both 3D structures are also very similar (Figure 3b). It was determined that the amino acids postulated by Aleshin and colleagues [5] as belonging to the active site and acarbose binding (Y337, W341, R343, D344, Q380, W390, W437, E438, E439, W599, R575, E636, W654 and L652) are well conserved in the SdGA model (Figure 3c, 3d and Table 1).

\subsection{Expression and purification of SdGA}

SdGA from $S$. degradans was synthesized and cloned into the pRSFDuet vector, as described in the Materials and Methods section. The plasmid named pRSF-DUET_SdGA was successfully expressed in E. coli BL21(DE3) Rosetta cells. The expression was optimized to obtain about $40 \%$ of SdGA in the soluble fraction (Figure 4, lane 5). Thus, soluble SdGA was purified to homogeneity by a single purification step using $\mathrm{Ni}^{2+}$ affinity chromatography. Using this procedure, we have obtained about 0.2 
$\mathrm{mg}$ of protein from about $5 \mathrm{~g}$ of $E$. coli cells. SdGA has a calculated molecular mass of $87.4 \mathrm{kDa}$ and produced a single band of about 90kDa on SDS-PAGE analysis (lane 8, Figure 4). The identity of the protein band was confirmed by immunoblotting using anti-penta-His antibodies (lane 9, Figure 4).

\subsection{Kinetic characterization of purified SdGA}

Purified SdGA showed more than $80 \%$ glucoamylase activity at $\mathrm{pH}$ values between 5.5 and 6.5, being pH 6 the optimum for the enzyme. Moreover, SdGA remains active over the range between pH 4.0 and pH 8.0 (Figure 5a).

The dependence of SdGA activity on the temperature was examined using $2 \%(\mathrm{w} / \mathrm{v})$ maltose in $0.1 \mathrm{M}$ sodium phosphate buffer $(\mathrm{pH} 6.0)$ at temperatures ranging from 10 to $50^{\circ} \mathrm{C}$. Figure $5 \mathrm{~b}$ shows that the activity of the SdGA was maximal at $39^{\circ} \mathrm{C}$. However, we found that the enzyme catalyzes the reaction with at least $50 \%$ of the $V_{\max }$ between 20 to $48^{\circ} \mathrm{C}$, showing about $20-30 \%$ of activity at $10-15^{\circ} \mathrm{C}$. The enthalpy of activation for the reaction calculated from the Arrhenius equation is $31.8 \mathrm{~kJ} / \mathrm{mol}$ (inset Figure $5 b)$. Thus, SdGA is able to catalyze the reaction in a wide range of temperatures as reported for other GAs, classified as cold-adapted enzymes, like a fungal GA from Tetracladium sp. [40] or the GA from Caulobacter crescentus [41].

To determine the kinetic parameters $S_{0.5}, n_{\mathrm{H}}$ and $V_{\max }$ (or $k_{\mathrm{cat}}$, to compare with other GAs, see Table $\mathrm{S} 1)$, GA activity was measured in $0.1 \mathrm{M}$ sodium phosphate buffer $(\mathrm{pH} 6.0)$ at $20^{\circ} \mathrm{C}$ and $39^{\circ} \mathrm{C}$, at increasing concentrations of maltose. Interestingly, SdGA shows no $\mathrm{Ca}^{2+}$ dependency for activity (not shown). At $39^{\circ} \mathrm{C}$, SdGA showed Michaelis kinetics with a $V_{\max }=6.1 \pm 0.5 \mathrm{U} / \mathrm{mg}\left(k_{\text {cat }}=8.9 \pm 1.1 \mathrm{~s}^{-1}\right)$, a $n_{\mathrm{H}}=1.1 \pm$ 0.1 and a $S_{0.5}=10.7 \pm 1.5 \mathrm{mM}$, while at $20^{\circ} \mathrm{C}$ the enzyme showed a $V_{\max }$ and $S_{0.5}$ about 2- and 4-fold lower $(2.7 \pm 0.22 \mathrm{U} / \mathrm{mg}$ and $2.5 \pm 0.63 \mathrm{mM}$, respectively), resulting in a 2-fold increase of the catalytic

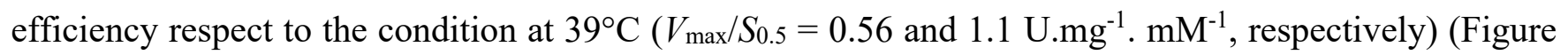
$6)$.

\subsection{Studies on thermal stability of SdGA}

Temperature stability assays were performed by incubating different aliquots of the enzyme without the substrate at $45^{\circ} \mathrm{C}$ and $50^{\circ} \mathrm{C}$ at different times, and the residual activity was measured under standard assay conditions. As suggested by the results showed in Figure 7a, SdGA is unstable when exposed at temperatures above $45^{\circ} \mathrm{C}$ in the absence of effectors. Inactivation is dependent on temperature and incubation time and follows first-order kinetics. Inactivation half times $\left(t_{0.5}\right)$ obtained were $9.8 \pm 0.7$ 
and $0.8 \pm 0.1 \mathrm{~min}$ for $45^{\circ} \mathrm{C}$ and $50^{\circ} \mathrm{C}$, respectively (Figure $7 \mathrm{a}$ ). The inactivation rate constants $(k)$ at $45^{\circ} \mathrm{C}$ and $50^{\circ} \mathrm{C}$ were calculated from the slope of the inset of Figure $7 \mathrm{a}\left(0.071 \pm 0.008\right.$ and $0.607 \pm 0.0 .83 \mathrm{~min}^{-}$ 1 , respectively).

We also tested the effect of different compounds on the thermal inactivation of SdGA at $45^{\circ} \mathrm{C}$. Thus, we incubated the enzyme in the presence of $0.1 \mathrm{mM}$ acarbose, $1 \mathrm{mM} \mathrm{Ca}^{2+}$ or $10 \%(\mathrm{v} / \mathrm{v})$ glycerol at different times, and the remaining SdGA activity was measured at $39^{\circ} \mathrm{C}$ (Figure $7 \mathrm{~b}$ ). The semi-log plots of the residual activity vs. time were linear at all temperatures, (inset Figure $7 \mathrm{~b}$ ) indicating that the inactivation follows first-order kinetics for all the metabolites tested.

We found that acarbose shows partial protection as indicated by the increase of the time required to obtain $50 \%$ of the initial activity $\left(t_{0.5}=44.3 \pm 2.5 \mathrm{~min}\right.$, while glycerol was less effective, showing a $t_{0.5}$ of $21.2 \pm 2.8 \mathrm{~min}$. In contrast, $\mathrm{Ca}^{2+}$ does not significantly modified the $t_{0.5}$ for the thermal inactivation of SdGA $\left(t_{0.5}=10.3 \pm 1.9 \mathrm{~min}.\right)$, compared to the $t_{0.5}$ showed by the enzyme incubated in the absence of effectors $\left(9.8 \pm 0.7 \mathrm{~min}\right.$.). The inactivation rate constants $k, D$-values and $t_{0.5}$ are shown in Table 2 . These data indicate that acarbose and to a lesser extent glycerol, are good protectors, albeit partially, against the thermal inactivation of the protein, while $\mathrm{Ca}^{2+}$ is a poor protective agent.

Results showed that SdGA is much thermolabile when compared with other characterized GAs. This characteristic, as well as the fact that the enzyme is active at low temperatures and that the activity rapidly decreases at temperatures over $42^{\circ} \mathrm{C}$, allow this enzyme to be classified as a possible cold-adapted enzyme [40, 42, 43].

\subsection{Analysis of flexible residues in SdGA}

One of the properties of cold-adapted enzymes is their increased flexibility either in the vicinity of the active site or in more distant parts of the protein molecule. Moreover, this flexibility has been associated to a decrease in the structural thermostability of cold-active enzymes, which is in agreement with the thermal inactivation of SdGA under moderate temperatures reported above [42-45]. In addition, cold-adapted enzymes usually contain a higher number of glycines, mainly in loop regions, and a lower number of prolines and arginines [45].

Thus, we carried out a study in order to compare the flexibility and composition of amino acids present in SdGA with those of other GAs from psychrophilic, cold-adapted and thermophilic organisms. FlexPred analysis shows that the CD of SdGA has similar number of flexible residues $(13.45 \% \mathrm{~F})$ compared with GAs from B. mediterranea (BmGA), Caulobacter sp. (CsGA) (about $15 \% \mathrm{~F}$ ) and 
Pseudoalteromonas species (about $14 \% \mathrm{~F}$, Table 3). This percentage is significantly higher than the percentage of flexible residues found in GAs from thermophilic bacteria such as those from S. Solfataricus $(7.44 \% \mathrm{~F})$, T. thermosaccharolyticum $(8.81 \% \mathrm{~F})$ or T. acidophilum $(5.38 \% \mathrm{~F})$. In addition, SdGA, BmGA, CsGA and Pseudoalteromonas species have higher glycine content (between 10.5 - 11.7 \%G) compared with the thermophilic GAs (between $5.5-9.7 \% \mathrm{G}$ ). It is important to highlight that the GAs from $B$. mediterranea, Caulobacter sp., Pseudoalteromonas species and Flavobacterium sp. are grouped with SdGA within the same region of the phylogenetic tree shown in Figure 2.

It was suggested that other properties of cold-adapted enzymes are (i) their higher amino acid content compared to the enzymes of thermophilic organisms, which have a more compact core and (ii) the existence of amino acid inserts or loops in regions near the active site [41-43]. The latter would also be related to the thermolabile characteristics of this group of enzymes.

Using Clustal W, we performed a sequence alignment of the catalytic domains of SdGA with the GAs used to analyze the flexible residues. Results show the presence of 5 insertions between 9 to 13 amino acids that are absent in all analyzed thermophilic GAs (Figure S1). Interestingly, 3 of these amino acid insertions are outside the conserved S1-S5 regions, while two of the inserts are inside the S3 and S5 regions. The results suggest that the presence of these amino acid insertions may be an adaptation of SdGA to catalyze the reaction at low and medium temperatures.

\section{Discussion}

Numerous works have been carried out on the characterization of the structure and function of GAs from fungi and yeasts, however, a few enzymes from prokaryotic organisms have been studied. The first bacterial GA cloned and expressed in E. coli cells was that of Clostridium sp. [46]. Clostridium GA has maximum activity at $\mathrm{pH}$ around 5 and an optimal temperature close to $70^{\circ} \mathrm{C}$. Subsequently, other GAs from thermophilic bacteria were characterized, such as those from $S$. solfataricus, T. thermosaccharolyticum or $T$. tengcongensis, which showed optimal temperatures between $60-90^{\circ} \mathrm{C}$ and an optimal acid pH, around 5 [5, 13] [47]. Other GAs from archaea such as T. acidophilum, Picrophilus torridus and Picrophilus oshimae, which showed optimal temperatures of around $90^{\circ} \mathrm{C}$ and $\mathrm{pH} 2.0$ [48] or Metanococcus jannaschii, with optimal temperature and $\mathrm{pH}$ of $80^{\circ} \mathrm{C}$ and 6.5 , respectively were recently described [12]. These GAs of archaea such as 
fungal GAs have higher specificity for larger substrates, such as starch, amylopectin, and glycogen, than for smaller maltooligosaccharides [49] [48] [50].

The common characteristic among the enzymes mentioned above is the high optimum temperature, which is desirable in various industrial processes such as the production of glucose and syrups [51]. However, there are very few reports on the characterization of GAs that work at low or medium temperatures. The latter would be relevant for certain processes such as cold starch hydrolysis for the production of bioethanol, as well as its use in the detergent and food industries, for the production of fine chemicals and in bioremediation processes [52]. [17, 40].

Saccharophagus degradans is a marine bacterium that could be defined as facultative psychrophilic or cold-tolerant, since although its optimal growth temperature is $37^{\circ} \mathrm{C}$, it can grow in the range of 5-40 ${ }^{\circ} \mathrm{C}$ [22]. As previously mentioned, this microorganism is related to the group of marine bacteria that degrade different complex polysaccharides with high efficiency that can be used as the only source of carbon and energy.

The results presented in this work indicate that SdGA has the ability to degrade maltose with a catalytic efficiency comparable to other described enzymes, including those from thermophilic organisms [46] (see Table S1) even at temperatures of around $10-20^{\circ} \mathrm{C}$. Sequence alignment analysis revealed that this protein has 5 conserved regions (S1-S5), also present in other GAs previously described [53]. The highest sequence identity was observed with marine GAs from G. polysaccharolyticus and G. agarilyticus (67\% and 66\% identity, respectively), However, SdGA also shows a high degree of identity with GAs of other organisms that have the ability to grow at low temperatures such as many Caulobacter species (around 54-57\% identity), or Bevundimonas species such as B. mediterranea (58\% identity), Pseudoalteromonas species such as P. arctica (56\% identity) and Flavobacterium sp. (56\% identity) [41]. Furthermore, the alignment of the CD of SdGA with those from the GAs mentioned above showed an increase of around 6\% of the identity (60 - 63\% identity), which reinforces the fact that SdGA shares common characteristics with these enzymes.

The 3D model for SdGA shows a high structural conservation of the residues involved in the acarbose binding and active site. This protein was shown to be composed of a barrel-shaped $\operatorname{CD}(\alpha / \alpha)_{6}$ and an N-terminal $\beta$-sandwich domain similar to the thermophilic GA of T. thermosaccharolyticum, a representative member of the GH15 family. By homology modeling, we identified two glutamic acid residues in SdGA, E513 and E745, which are located at similar positions in other GAs, described as involved in the hydrolysis of substrates such as E438/E636 and E179/E400 from $T$. thermosaccharolyticum and A. awamori GAs, respectively [5, 54].

SdGA is active in an acidic environment, and this is characteristic of the catalytic mechanism of GAs. The widely accepted model for the action of GAs is the formation of oxocarbenium ions, which 
involves the transfer of protons to the glycosidic oxygen of the cleavable bond from a general acid catalyst, and a nucleophilic attack of water assisted by a general base catalyst [51, 55]. Unlike alpha-amylases where catalytic acid (proton donor) and base (nucleophile) are glutamate and aspartate residues, respectively, in GAs, glutamate residues act as acidic and basic catalysts [56, 57].

SdGA showed maximum activity at $\mathrm{pH} 6.0$, similar to the optimal $\mathrm{pH}$ value of other microbial GAs, while the optimal temperature was $39^{\circ} \mathrm{C}[13,47,58-60]$. Furthermore, the protein showed an activity greater than $50 \%$ in a wide range of $\mathrm{pH}(4.5-7)$ and temperatures $\left(20-48^{\circ} \mathrm{C}\right)$, retaining around $30 \%$ of its activity at temperatures of $15^{\circ} \mathrm{C}$, and a high catalytic efficiency, both desirable characteristics of coldadapted enzymes.

All the kinetic parameters $\left(K_{\mathrm{m}}, k_{\mathrm{cat}}\right.$ and $\left.V_{\max }\right)$ obtained for SdGA were within the previously reported values for microbial GAs (Table S1), however, SdGA showed no $\mathrm{Ca}^{2+}$ dependency and no inhibition at high concentrations of maltose. These data are comparable with those recently reported for the GA of Caulobacter crescentus [41]. This cold tolerant proteobacterium has a GA that shows an optimal temperature of $30^{\circ} \mathrm{C}$ and an optimal $\mathrm{pH}$ of 5.0, and is also active at low temperatures, showing a catalytic efficiency similar to the enzymes characterized from thermophilic organisms. The results obtained indicate that SdGA can be defined as a cold-adapted enzyme, with catalytic efficiencies comparable to other thermophilic GAs even at temperatures of $20^{\circ} \mathrm{C}$.

Because most of the GAs that are currently being used in the starch saccharification stage have low activity at $\mathrm{pH}$ 6.0-6.5 [61], the use of SdGA that has optimal activity at pH 6.0 and it is active at low and medium temperatures, it represents a good alternative for this process because, for example, it would not be necessary to adjust the $\mathrm{pH}$ to $4.0-4.5$, and thus, costs would be reduced. Furthermore, many GAs undergo substrate inhibition at high substrate concentrations [41,62], while SdGA is not inhibited by maltose at concentrations greater than ten times the $S_{0.5}$ value.

At temperatures above $45^{\circ} \mathrm{C}$ the SdGA activity decreased considerably. Thermal stability tests showed that $\mathrm{SdGA}$ is labile at temperatures above $45^{\circ} \mathrm{C}$. These parameters are lower than those shown by fungal GAs, which have higher thermostability and show optimal temperatures between $40-70^{\circ} \mathrm{C}[63$, 64]. Thermal stability analyses in the presence of metabolites showed that $\mathrm{Ca}^{2+}$ does not affect the stability of SdGA, while glycerol and acarbose partially stabilize the enzyme. In addition, $\mathrm{Ca}^{2+}$ also did not affect SdGA activity. The activity of fungal GAs is usually affected by $\mathrm{Ca}^{2+}[65,66]$ and only a few GAs show activity in the absence of this cation [67]. From an industrial point of view, this is also a desirable feature since adding salts to any process would increase costs and / or could lead to unwanted side effects. 
Finally, it was reported that at the structural level, cold-adapted enzymes are more flexible than their thermostable counterparts [43]. We found that SdGA shows similar flexibility than other GAs from psychrophilic or cold-tolerant organisms. Moreover, SdGA shows higher flexibility compared with thermophilic GAs. We also found that SdGA has a higher amino acid content respect to thermophilic GAs due to several insertions within its $\mathrm{CD}$ and also contains higher glycine content. It was reported that glycine residues provide flexibility to enzyme active sites [68]. These amino acid insertions, as well as the higher flexible residues and glycine content could explain not only the thermolability of SdGA, but also its ability to catalyze the reactions at low or mild temperatures. It was demonstrated that the features that make an enzyme more flexible, such as higher amino acid content, higher glycine content, and high flexible residue content near the active site compensates the low kinetic energy in cold environments [42, 43].

In summary, the novel GA from $S$. degradans has an overall structure like other GAs, showing a high structural conservation of the active site. SdGA is active over a broad range of $\mathrm{pH}$ and temperatures, it has no calcium dependency and shows no inhibition at high substrate concentrations, but an increased thermolability at moderate temperatures. We also found that SdGA is more flexible than its thermostable counterparts due to the higher content of flexible and glycine residues and a larger CD, due to several amino acid insertions in the vicinity of the conserved regions of this domain. These characteristics allow it to be classified as a cold-adapted enzyme. We propose that this novel SdGA, might have potential applications for use in different industrial processes that require an efficient alpha glucosidase activity at low/mild temperatures, such as biofuel production.

\section{Acknowledgements}

NW (doctoral fellow), NH (postdoctoral fellow), MVB and DFGC (research scientists) are members of the National Research Council from Argentina (CONICET).

Funding: This study was funded by ANPCyT (PICT 2018-01440) and CONICET (PIP 2015-0476). 


\section{References}

1. Marin-Navarro, J. \& Polaina, J. (2011) Glucoamylases: structural and biotechnological aspects, Applied microbiology and biotechnology. 89, 1267-73.

2. Lombard, V., Golaconda Ramulu, H., Drula, E., Coutinho, P. M. \& Henrissat, B. (2014) The carbohydrate-active enzymes database (CAZy) in 2013, Nucleic acids research. 42, D490-5.

3. Liu, Y. N., Lai, Y. T., Chou, W. I., Chang, M. D. \& Lyu, P. C. (2007) Solution structure of family 21 carbohydrate-binding module from Rhizopus oryzae glucoamylase, The Biochemical journal. 403, 21-30.

4. Sorimachi, K., Le Gal-Coeffet, M. F., Williamson, G., Archer, D. B. \& Williamson, M. P. (1997) Solution structure of the granular starch binding domain of Aspergillus niger glucoamylase bound to betacyclodextrin, Structure. 5, 647-61.

5. Aleshin, A. E., Feng, P. H., Honzatko, R. B. \& Reilly, P. J. (2003) Crystal structure and evolution of a prokaryotic glucoamylase, Journal of molecular biology. 327, 61-73.

6. Ball, S. G. \& Morell, M. K. (2003) From bacterial glycogen to starch: understanding the biogenesis of the plant starch granule, Annual review of plant biology. 54, 207-33.

7. Zeeman, S. C., Kossmann, J. \& Smith, A. M. (2010) Starch: its metabolism, evolution, and biotechnological modification in plants, Annual review of plant biology. 61, 209-34.

8. Busi, M. V., Barchiesi, J., Martin, M. \& Gomez-Casati, D. F. (2013) Starch metabolism in green algae, Starch/Stärke. 66, 28-40.

9. Ball, S., Guan, H. P., James, M., Myers, A., Keeling, P., Mouille, G., Buleon, A., Colonna, P. \& Preiss, J. (1996) From glycogen to amylopectin: a model for the biogenesis of the plant starch granule, Cell. 86, 349-52.

10. Kumar, P. \& Satyanarayana, T. (2009) Microbial glucoamylases: characteristics and applications, Critical reviews in biotechnology. 29, 225-55.

11. Busic, A., Mardetko, N., Kundas, S., Morzak, G., Belskaya, H., Ivancic Santek, M., Komes, D., Novak, S. \& Santek, B. (2018) Bioethanol Production from Renewable Raw Materials and Its Separation and Purification: A Review, Food technology and biotechnology. 56, 289-311.

12. Uotsu-Tomita, R., Tonozuka, T., Sakai, H. \& Sakano, Y. (2001) Novel glucoamylase-type enzymes from Thermoactinomyces vulgaris and Methanococcus jannaschii whose genes are found in the flanking region of the alpha-amylase genes, Applied microbiology and biotechnology. 56, 465-73.

13. Kim, M. S., Park, J. T., Kim, Y. W., Lee, H. S., Nyawira, R., Shin, H. S., Park, C. S., Yoo, S. H., Kim, Y. R., Moon, T. W. \& Park, K. H. (2004) Properties of a novel thermostable glucoamylase from the hyperthermophilic archaeon Sulfolobus solfataricus in relation to starch processing, Applied and environmental microbiology. 70, 3933-40.

14. Dock, C., Hess, M. \& Antranikian, G. (2008) A thermoactive glucoamylase with biotechnological relevance from the thermoacidophilic Euryarchaeon Thermoplasma acidophilum, Applied microbiology and biotechnology. 78, 105-14.

15. Aquino, A. C., Jorge, J. A., Terenzi, H. F. \& Polizeli, M. L. (2001) Thermostable glucose-tolerant glucoamylase produced by the thermophilic fungus Scytalidium thermophilum, Folia microbiologica. 46, 11-6.

16. Michelin, M., Ruller, R., Ward, R. J., Moraes, L. A., Jorge, J. A., Terenzi, H. F. \& Polizeli Mde, L. (2008) Purification and biochemical characterization of a thermostable extracellular glucoamylase produced by the thermotolerant fungus Paecilomyces variotii, Journal of industrial microbiology \& biotechnology. 35, 17-25. 
17. Yingling, B., Li, C., Honglin, W., Xiwen, Y. \& Zongcheng, Y. (2011) Multi-objective optimization of bioethanol production during cold enzyme starch hydrolysis in very high gravity cassava mash, Bioresource technology. 102, 8077-84.

18. Swain, M. R., Natarajan, V. \& Krishnan, C. (2017) Marine Enzymes and Microorganisms for Bioethanol Production, Advances in food and nutrition research. 80, 181-197.

19. Fang, W., Xue, S., Deng, P., Zhang, X., Wang, X., Xiao, Y. \& Fang, Z. (2019) AmyZ1: a novel alphaamylase from marine bacterium Pontibacillus sp. ZY with high activity toward raw starches, Biotechnology for biofuels. 12, 95.

20. Homaei, A., Ghanbarzadeh, M. \& Monsef, F. (2016) Biochemical features and kinetic properties of alpha-amylases from marine organisms, International journal of biological macromolecules. 83, 306-14. 21. Suriya, J., Bharathiraja, S., Krishnan, M., Manivasagan, P. \& Kim, S. K. (2016) Marine Microbial Amylases: Properties and Applications, Advances in food and nutrition research. 79, 161-177.

22. Ekborg, N. A., Gonzalez, J. M., Howard, M. B., Taylor, L. E., Hutcheson, S. W. \& Weiner, R. M. (2005) Saccharophagus degradans gen. nov., sp. nov., a versatile marine degrader of complex polysaccharides, International journal of systematic and evolutionary microbiology. 55, 1545-9.

23. Larkin, M. A., Blackshields, G., Brown, N. P., Chenna, R., McGettigan, P. A., McWilliam, H., Valentin, F., Wallace, I. M., Wilm, A., Lopez, R., Thompson, J. D., Gibson, T. J. \& Higgins, D. G. (2007) Clustal W and Clustal X version 2.0, Bioinformatics. 23, 2947-8.

24. Kumar, S., Stecher, G. \& Tamura, K. (2016) MEGA7: Molecular Evolutionary Genetics Analysis Version 7.0 for Bigger Datasets, Molecular biology and evolution. 33, 1870-4.

25. Jones, D. T., Taylor, W. R. \& Thornton, J. M. (1992) The rapid generation of mutation data matrices from protein sequences, Computer applications in the biosciences: CABIOS. 8, 275-82.

26. Kuznetsov, I. B. \& McDuffie, M. (2008) FlexPred: a web-server for predicting residue positions involved in conformational switches in proteins, Bioinformation. 3, 134-6.

27. Pons, J. L. \& Labesse, G. (2009)@TOME-2: a new pipeline for comparative modeling of proteinligand complexes, Nucleic acids research. 37, W485-91.

28. Sippl, M. J. (1993) Recognition of errors in three-dimensional structures of proteins, Proteins. 17, 355-62.

29. Wiederstein, M. \& Sippl, M. J. (2007) ProSA-web: interactive web service for the recognition of errors in three-dimensional structures of proteins, Nucleic acids research. 35, W407-10.

30. Luthy, R., Bowie, J. U. \& Eisenberg, D. (1992) Assessment of protein models with three-dimensional profiles, Nature. 356, 83-5.

31. Fox, J. D. \& Robyt, J. F. (1991) Miniaturization of three carbohydrate analyses using a microsample plate reader, Analytical biochemistry. 195, 93-6.

32. Bradford, M. M. (1976) A rapid and sensitive method for the quantitation of microgram quantities of protein utilizing the principle of protein-dye binding, Analytical biochemistry. 72, 248-54.

33. Brooks, S. P. (1992) A simple computer program with statistical tests for the analysis of enzyme kinetics, BioTechniques. 13, 906-11.

34. Gouzi, H., Depagne, C. \& Coradin, T. (2012) Kinetics and thermodynamics of the thermal inactivation of polyphenol oxidase in an aqueous extract from Agaricus bisporus, Journal of agricultural and food chemistry. 60, 500-6.

35. Laemmli, U. K. (1970) Cleavage of structural proteins during the assembly of the head of bacteriophage T4, Nature. 227, 680-5.

36. Bollag, D. M., Rozycki, M. D. \& Edelstein, S. J. (1996) Protein Methods, 2nd edn., Wiley-Liss, New York. 
37. Roche, D. B., Viet, P. D., Bakulina, A., Hirsh, L., Tosatto, S. C. E. \& Kajava, A. V. (2018) Classification of beta-hairpin repeat proteins, Journal of structural biology. 201, 130-138.

38. Drozdetskiy, A., Cole, C., Procter, J. \& Barton, G. J. (2015) JPred4: a protein secondary structure prediction server, Nucleic acids research. 43, W389-94.

39. Coutinho, P. M. \& Reilly, P. J. (1994) Structure-function relationships in the catalytic and starch binding domains of glucoamylase, Protein engineering. 7, 393-400.

40. Carrasco, M., Alcaino, J., Cifuentes, V. \& Baeza, M. (2017) Purification and characterization of a novel cold adapted fungal glucoamylase, Microbial cell factories. 16, 75.

41. Sakaguchi, M., Matsushima, Y., Nankumo, T., Seino, J., Miyakawa, S., Honda, S., Sugahara, Y., Oyama, F. \& Kawakita, M. (2014) Glucoamylase of Caulobacter crescentus CB15: cloning and expression in Escherichia coli and functional identification, AMB Express. 4, 5.

42. Smalas, A. O., Leiros, H. K., Os, V. \& Willassen, N. P. (2000) Cold adapted enzymes, Biotechnology annual review. $6,1-57$.

43. Siddiqui, K. S. \& Cavicchioli, R. (2006) Cold-adapted enzymes, Annual review of biochemistry. 75, 403-33.

44. Chiuri, R., Maiorano, G., Rizzello, A., del Mercato, L. L., Cingolani, R., Rinaldi, R., Maffia, M. \& Pompa, P. P. (2009) Exploring local flexibility/rigidity in psychrophilic and mesophilic carbonic anhydrases, Biophysical journal. 96, 1586-96.

45. Michetti, D., Brandsdal, B. O., Bon, D., Isaksen, G. V., Tiberti, M. \& Papaleo, E. (2017) A comparative study of cold- and warm-adapted Endonucleases A using sequence analyses and molecular dynamics simulations, PloS one. 12, e0169586.

46. Ohnishi, H., Kitamura, H., Minowa, T., Sakai, H. \& Ohta, T. (1992) Molecular cloning of a glucoamylase gene from a thermophilic Clostridium and kinetics of the cloned enzyme, European journal of biochemistry. 207, 413-8.

47. Zheng, Y., Xue, Y., Zhang, Y., Zhou, C., Schwaneberg, U. \& Ma, Y. (2010) Cloning, expression, and characterization of a thermostable glucoamylase from Thermoanaerobacter tengcongensis MB4, Applied microbiology and biotechnology. 87, 225-33.

48. Serour, E. \& Antranikian, G. (2002) Novel thermoactive glucoamylases from the thermoacidophilic Archaea Thermoplasma acidophilum, Picrophilus torridus and Picrophilus oshimae, Antonie van Leeuwenhoek. 81, 73-83.

49. He, Z., Zhang, L., Mao, Y., Gu, J., Pan, Q., Zhou, S., Gao, B. \& Wei, D. (2014) Cloning of a novel thermostable glucoamylase from thermophilic fungus Rhizomucor pusillus and high-level co-expression with alpha-amylase in Pichia pastoris, BMC biotechnology. 14, 114.

50. Hua, H., Luo, H., Bai, Y., Wang, K., Niu, C., Huang, H., Shi, P., Wang, C., Yang, P. \& Yao, B. (2014) A thermostable glucoamylase from Bispora sp. MEY-1 with stability over a broad $\mathrm{pH}$ range and significant starch hydrolysis capacity, PloS one. 9, e113581.

51. Sauer, J., Sigurskjold, B. W., Christensen, U., Frandsen, T. P., Mirgorodskaya, E., Harrison, M., Roepstorff, P. \& Svensson, B. (2000) Glucoamylase: structure/function relationships, and protein engineering, Biochimica et biophysica acta. 1543, 275-293.

52. Gerday, C., Aittaleb, M., Bentahir, M., Chessa, J. P., Claverie, P., Collins, T., D'Amico, S., Dumont, J., Garsoux, G., Georlette, D., Hoyoux, A., Lonhienne, T., Meuwis, M. A. \& Feller, G. (2000) Coldadapted enzymes: from fundamentals to biotechnology, Trends in biotechnology. 18, 103-7.

53. Coutinho, P. M. \& Reilly, P. J. (1994) Structural similarities in glucoamylase by hydrophobic cluster analysis, Protein engineering. 7, 749-60. 
54. Aleshin, A. E., Firsov, L. M. \& Honzatko, R. B. (1994) Refined structure for the complex of acarbose with glucoamylase from Aspergillus awamori var. X100 to 2.4-A resolution, The Journal of biological chemistry. 269, 15631-9.

55. Tanaka, Y., Tao, W., Blanchard, J. S. \& Hehre, E. J. (1994) Transition state structures for the hydrolysis of alpha-D-glucopyranosyl fluoride by retaining and inverting reactions of glycosylases, The Journal of biological chemistry. 269, 32306-12.

56. Sierks, M. R. \& Svensson, B. (2000) Energetic and mechanistic studies of glucoamylase using molecular recognition of maltose $\mathrm{OH}$ groups coupled with site-directed mutagenesis, Biochemistry. 39, 8585-92.

57. Harris, E. M., Aleshin, A. E., Firsov, L. M. \& Honzatko, R. B. (1993) Refined structure for the complex of 1-deoxynojirimycin with glucoamylase from Aspergillus awamori var. X100 to 2.4-A resolution, Biochemistry. 32, 1618-26.

58. Campos, L. \& Felix, C. R. (1995) Purification and Characterization of a Glucoamylase from Humicola grisea, Applied and environmental microbiology. 61, 2436-8.

59. James, J. A., Berger, J. L. \& Lee, B. H. (1997) Purification of glucoamylase from Lactobacillus amylovorus ATCC 33621, Current microbiology. 34, 186-91.

60. Wu, X., Wang, Y., Tong, B., Chen, X. \& Chen, J. (2018) Purification and biochemical characterization of a thermostable and acid-stable alpha-amylase from Bacillus licheniformis B4-423, International journal of biological macromolecules. 109, 329-337.

61. Xu, Q. S., Yan, Y. S. \& Feng, J. X. (2016) Efficient hydrolysis of raw starch and ethanol fermentation: a novel raw starch-digesting glucoamylase from Penicillium oxalicum, Biotechnology for biofuels. 9, 216. 62. Takahashi, T., Inokuchi, N. \& Irie, M. (1981) Purification and characterization of a glucoamylase from Aspergillus saitoi, Journal of biochemistry. 89, 125-34.

63. Xian, L. \& Feng, J. X. (2018) Purification and biochemical characterization of a novel mesophilic glucoamylase from Aspergillus tritici WZ99, International journal of biological macromolecules. 107, 1122-1130.

64. Bagheri, A., Khodarahmi, R. \& Mostafaie, A. (2014) Purification and biochemical characterisation of glucoamylase from a newly isolated Aspergillus niger: relation to starch processing, Food chemistry. $161,270-8$.

65. Vihinen, M. \& Mantsala, P. (1989) Microbial amylolytic enzymes, Critical reviews in biochemistry and molecular biology. 24, 329-418.

66. Benassi, V. M., Pasin, T. M., Facchini, F. D., Jorge, J. A. \& Teixeira de Moraes Polizeli Mde, L. (2014) A novel glucoamylase activated by manganese and calcium produced in submerged fermentation by Aspergillus phoenicis, Journal of basic microbiology. 54, 333-9.

67. Soni, S. K., Kaur, A. \& Gupta, J. K. (2003) A solid state fermentation based bacterial $\alpha$-amylase and fungal glucoamylase system and its suitability for the hydrolysis of wheat starch. Proc Biochem. 39, 185192.

68. Yan, B. X. \& Sun, Y. Q. (1997) Glycine residues provide flexibility for enzyme active sites, The Journal of biological chemistry. 272, 3190-4. 


\section{Figure Legends}

Figure 1. Structure domain and sequence alignment of SdGA. a) Structure domain of SdGA: SP: signal peptide, GH15_N: glycoside hydrolase family 15 N-terminal domain, LR: linker region, GH15L-CD: Cterminal glycoside hydrolase family 15-like CD. Numbers at the top indicate the amino acid positions at the beginning and end of each domain b) Sequence alignment of the CD of SdGA with other GAs: Aspergillus awamori (PDB entry: 1GLM); Saccharophagus degradans (SdGA) ABD79864.1; Caldanaerobacter subterraneus subsp. tengcongensis AAM25005.1; Thermoanaerobacterium thermosaccharolyticum (PDB entry: 1LF6) and Clostridium sp. BAA02251.1. Boxes show the five highly conserved regions (S1-S5) found in GAs. Red arrows indicate two catalytic residues, E513 and E745 (SdGA numbering). The conserved residues are marked with * (green inside the rectangles or gray outside them) and with : and . (pink and yellow) the conservative substitutions.

Figure 2. Phylogenetic Analysis of GAs. Phylogenetic tree showing the relationship among GAs from different microorganisms based on amino acid sequence homology. Multiple sequence alignments were done using Clustal W program and the phylogenetic analysis was carried out by Maximum Likelihood method. The unrooted phylogenetic tree is shown using MEGA7 program [24]. The sequences were retrieved from NCBI (http://www.ncbi.nlm.nih.gov/). The accession numbers are: WP_047408988.1 glucan 1,4-alpha-glucosidase Caulobacter sp. OV484, WP_013080031.1 glucan 1,4-alpha-glucosidase Caulobacter segnis, BAO51876.1 glucoamylase Caulobacter vibrioides CB15, WP_116488500.1 glucan 1,4-alpha-glucosidase Caulobacter radicis, WP_101713990.1 glucan 1,4-alpha-glucosidase Caulobacter flavus, WP_154725846.1 glucan 1,4-alpha-glucosidase Brevundimonas mediterranea, WP_135193440.1 glucan 1,4-alpha-glucosidase Brevundimonas intermedia, WP_161638549.1 glucan 1,4-alphaglucosidase Flavobacterium sp. BBQ-18, WP_112861449.1 glucan 1,4-alpha-glucosidase Brevundimonas vesicularis, WP_049722861.1 glucan 1,4-alpha-glucosidase Gilvimarinus polysaccharolyticus, WP_041522105.1 glucan 1,4-alpha-glucosidase Gilvimarinus agarilyticus, ABD79864.1 glucoamylase Saccharophagus degradans (marked), WP_127699498.1 glucan 1,4-alpha-glucosidase Rheinheimera riviphila, WP_039912603.1 glucan 1,4-alpha-glucosidase Cellvibrio mixtus, WP_012486394.1 glucan 1,4-alpha-glucosidase Cellvibrio japonicus, WP_152387530.1 glucan 1,4-alpha-glucosidase Azotobacter salinestris, WP_039806303.1 glucan 1,4-alpha-glucosidase Azotobacter chroococcum, WP_099472013.1 glucan 1,4-alpha-glucosidase Emcibacter congregatus, WP_130597406.1 glucan 1,4-alpha-glucosidase Shewanella maritima, WP_105053773.1 glucan 1,4-alpha-glucosidase Psychrosphaera saromensis, WP_169043549.1 glucan 1,4-alpha-glucosidase Pseudoalteromonas arctica, WP_010557466.1 glucan 1,4-alpha-glucosidase Pseudoalteromonas marina, WP_149602793.1 glucan 1,4-alpha-glucosidase Pseudoalteromonas distincta, WP_010978811.1 glucoamylase Sulfurisphaera tokodaii, AAB99630.1 glucoamylase Methanocaldococcus jannaschii DSM 2661, AAK42610.1 glucoamylase Sulfolobus solfataricus P2, AEW05506.1 glucoamylase Sulfobacillus acidophilus DSM 10332, WP_011178293.1 glucoamylase Picrophilus torridus, WP_010916686.1 glucoamylase Thermoplasma volcanium, WP_010900770.1 glucoamylase Thermoplasma acidophilum, Q9LBQ9 glucodextranase Arthrobacter globiformis, AAM25005.1 glucoamylase Caldanaerobacter subterraneus subsp. tengcongensis MB4, O85672 glucoamylase Thermoanaerobacterium thermosaccharolyticum, BAC80264.2 glucoamylase Clostridium thermoamylolyticum BAA02251.1 glucoamylase Clostridium sp., AJQ18465.1 glucoamylase Saccharomycopsis fibuligera AAA20560.1, glucoamylase Saccharomyces cerevisiae var. diastaticus, 
CAA86997.1 glucoamylase Blastobotrys adeninivorans, BAA00033.1 glucoamylase Rhizopus oryzae, BAA25205.1 glucoamylase Aspergillus oryzae, CAA47707.1 glucan 1,4-alpha-glucosidase Neurospora crassa, P69327 glucoamylase Aspergillus awamori and GAQ47133.1 glucoamylase Aspergillus niger. Blue: marine bacterial GAs, black: non-marine bacterial GAs, red: archaeal GAs, green: fungal GAs

Figure 3. Homology Modelling of SdGA. a) Proposed model for SdGA (left) and structural model of $T$. thermosaccharolyticum GA (PDB entry: 1LF6, right). b) Superposition of SdGA (red) and 1LF6 (cyan). Superposition between SdGA model and 1LF6 structure showing the residues involved in the active site in absence (c) and presence of acarbose (d). SdGA residues are shown in red, 1LF6 residues are shown in cyan and the catalytic residues are marked in black. In d, bound acarbose is shown in black and A, B, C and $\mathrm{D}$ on the acarbose molecule represents the four subunits of the tetrasaccharide.

Figure 4. Expression analysis and purification of recombinant SdGA from E. coli cells. SDS-PAGE analysis followed by Coomasie Blue stain of: Lane 1: supernatant of crude extract from BL21 (DE3) Rosetta without induction; Lanes 2, 4 and 6: insoluble proteins after 1, 2 and $3 \mathrm{~h}$ of induction, respectively; Lanes 3, 5 and 7: soluble proteins after 1, 2 and $3 \mathrm{~h}$ induction, respectively; Lane 8: recombinant purified SdGA. Lane 9: western blot analysis of SdGA followed by incubation with anti-penta-His antibodies. Numerals on the left indicate molecular masses (MM, in $\mathrm{kDa}$ ) of the Pre-stained SDS-PAGE standard low range (Thermo Fisher Scientific).

Figure 5. Effect of $\mathrm{pH}$ and temperature on the activity of SdGA. a) Effect of $\mathrm{pH}$ on the activity of recombinant SdGA. Activity was assayed with maltose as substrate using $0.1 \mathrm{M}$ sodium acetate buffer ( $\mathrm{pH} 3.6-5.5$ ) or $0.1 \mathrm{M}$ sodium phosphate buffer $\left(\mathrm{pH} 5.8-8.0\right.$ ), at $39^{\circ} \mathrm{C}$. b) Effect of the temperature on the activity of SdGA. Activity was assayed with maltose as substrate using $0.1 \mathrm{M}$ sodium phosphate buffer at $\mathrm{pH}$ 6.0. Inset: Arrhenius plots for the activity of SdGA assayed at different temperatures. All data are the means of 3 independent experiments $\pm \mathrm{SD}$.

Figure 6. Maltose saturation plots for SdGA. SdGA activity was measured with increasing concentrations of maltose at $20^{\circ} \mathrm{C}$ (empty circles) or $39^{\circ} \mathrm{C}$ (black circles). See materials and methods for details.

Figure 7. Thermostability of SdGA. (a) The enzyme was incubated at $45^{\circ} \mathrm{C}$ (black circles) or $50^{\circ} \mathrm{C}$ (empty circles) for different time intervals and the residual activity was measured at $39^{\circ} \mathrm{C}$ as described in Materials and Methods. The inactivation rate constants $(k)$ were determined from the slopes of the logarithmic plot of activity vs. time (see inset). (b) Analysis of the thermostability of SdGA at $45^{\circ} \mathrm{C}$ in the absence (empty squares) or presence of different metabolites: $1 \mathrm{mM} \mathrm{Ca}^{2+}$ (black triangles), $10 \%$ (v/v) glycerol (empty circles) and $0.1 \mathrm{mM}$ acarbose (black squares). The inactivation rate constants $(k)$ for each condition were calculated as described in Fig. 7A (inset). All data are the means of 3 independent experiments \pm SD. 
Table 1. Amino acid residues involved in catalysis and acarbose binding in tGA and SdGA.

tGA SdGA Function

Y337 Y381 Close contact (3.3 A) with C7. Unit A of acarbose

W341 W385 Close contact (3.5 ̊) with C6. Unit A of acarbose

R343 R387 H-bond O3 and O4. Unit A of acarbose

D344 D388 H-bond O6. Unit A of acarbose

Q380 Q433 H-bond O6. Unit C of acarbose

W390 W443 Hydrophobic interactions with Unit C and D of acarbose

W437 W512 H-bond O3. Unit B of acarbose

E438 E513 Catalytic acid residue.

E439 E514 H-bond O2. Unit B of acarbose

R575 R665 H-bond O2. Unit A of acarbose/H-bond O3. Unit B of acarbose

W599 W696 Contribute to the formation of a large hydrophobic wall

E636 E745 Catalytic base residue

W654 W773 Contribute to the formation of a large hydrophobic

Ref:, O2, $\mathrm{O} 3$ and $\mathrm{O} 6$ oxygen atoms in acarbose, $\mathrm{C} 6$ and $\mathrm{C} 7$ carbon atoms in acarbose, Unit $\mathrm{A}$, Unit B and Unit $\mathrm{C}$ are subunits of acarbose. H-bond means that an hydrogen bond is stabilized. tGA: GA from Thermoanaerobacterium thermosaccharolyticum. 
Table 2. $k, D$ and $t_{0.5}$ values for the thermal inactivation of SdGA in the presence of different compounds at $45^{\circ} \mathrm{C}$.

\begin{tabular}{llcr}
\hline Compound & $\boldsymbol{k}\left(\mathbf{m i n}^{-\mathbf{1}}\right)$ & $\boldsymbol{D}(\mathbf{m i n})$ & $\boldsymbol{t}_{\mathbf{0 . 5}}(\mathbf{m i n})$ \\
\hline n.a. & $0.071 \pm 0.008$ & $32.4 \pm 4.2$ & $9.8 \pm 0.7$ \\
$\mathrm{Ca}^{2+} 1 \mathrm{mM}$ & $0.064 \pm 0.004$ & $35.9 \pm 3.9$ & $10.3 \pm 1.9$ \\
Glycerol 10\% (v/v) & $0.029 \pm 0.003$ & $79.4 \pm 6.8$ & $21.2 \pm 2.8$ \\
acarbose 0.1 mM & $0.016 \pm 0.002$ & $143.9 \pm 12.3$ & $44.3 \pm 3.5$ \\
\hline
\end{tabular}

Ref: $k$, termal inactivation constant; $D$, Decimal reduction time; $t_{0.5}$, half time of inactivation. Mean values \pm SD are reported. 
Table 3. Percentage of flexible and glycine residues in the catalytic domain of various GAs

Enzyme (organism)

SdGA

Brevundimonas mediterranea

Caulobacter sp.

Pseudoalteromonas arctica

Pseudoalteromonas distincta

Pseudoalteromonas marina

Flavobacterium sp.

Sulfolobus solfataricus

Thermoplasma acidophilum

Thermoanaerobacterium thermosaccharolyticum

Caldanaerobacter subterraneus subsp. tengcongensis
$\% \mathrm{G}$

$\% \mathbf{F}$

10.51

11.47

11.66

15.13

10.67

14.66

10.81

10.76

11.54

13.96

5.47

7.44

5.67

5.38

7.90

8.81

9.73

Ref: $\% \mathrm{G}$ and $\% \mathrm{~F}$ are the percentage of glicine and flexible residues, respectively, in the $\mathrm{CD}$ of each GA. Flexible residues were calculated using FlexPred (http://flexpred.rit.albany.edu). The accesion number of GAs are: ABD79864.1 Saccharophagus degradans, WP_154725846 Brevundimonas mediterranea, WP_047408988.1 Caulobacter sp., WP_169043549.1 Pseudoalteromonas arctica, WP_149602793.1 Pseudoalteromonas distincta, WP_010557466.1 Pseudoalteromonas marina, WP_161638549.1 Flavobacterium sp. BBQ-18, AAK42610.1 Sulfolobus solfataricus, WP_010900770.1 Thermoplasma acidophilum, AAC24003.1 Thermoanaerobacterium thermosaccharolyticum, AAM25005.1 Caldanaerobacter subterraneus subsp. tengcongensis. 
Figure 1

a

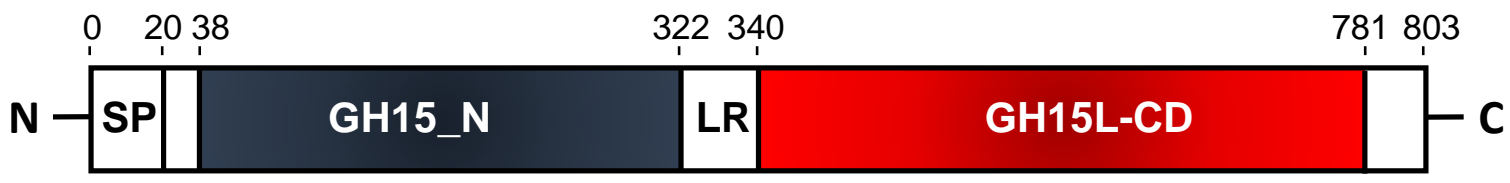

b

S1

GA-A. awamori GA-S.degrad GA-C. subter GA-T. thermo GA-Clostrid

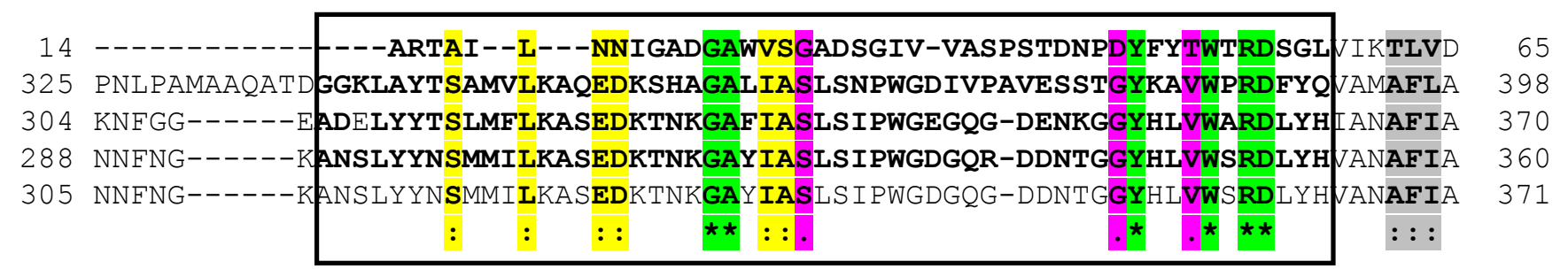

\section{S2}

GA-A.awamori 105 GA-S.degrad 432 GA-C.subter 395

GA-T.thermo 385 EP KFNVDETAYTGSWGRPQRDGPALRATAMIGFGQWLL 142 LQKTHVDGT---LEWYAVQLDQTAM--PIMI GWRLWQA 464 QNTWINGD---PYWNGIQMDEQAD--PIIIAYHLKRY 427 PQNTWISGK---PYWTGIQLDEQAD--PIIISYRLKRY 417

GA-Clostrid 396

$$
\text { PQNTWISGK---PYWTGIQLDEQAD--PIIISYRLRRY } 428
$$

\section{S3}

GA-A. awamori

$\mathrm{GA}-S$. degrad

GA-C.subter

153 IVWPLVR 475 WYTVMLK

429 LYEKLVK

GA-T . thermo

419 LYDSLVK

GA-Clostrid

430 LYDSLVK

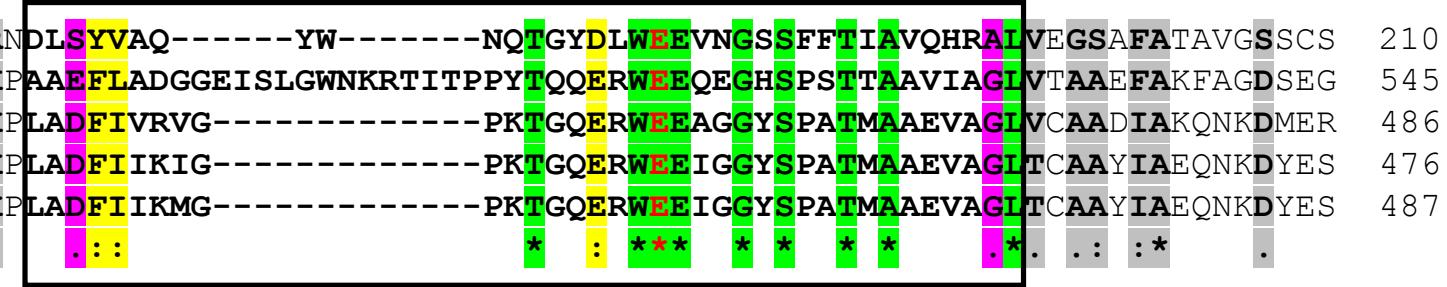


Figure 1b (cont.)

\section{S4}

GA-A. awamori 295

GA-S.degrad 656

GA-C.subter 582

GA-T.thermo 572

GA-Clostrid 583

\begin{tabular}{|c|c|c|}
\hline $\mathbf{S D S E}$ & AVAVGRYPEDSYYNGNPWFLCTLAAAEQLYD--ALYQWDKQGSLEITDVSLDFF & SGAATGTYSSSSSTYS-- \\
\hline NG & AVGWRRYGGDGYGETTS--------TGEGYGHGGTMHPDQRGRI----------WPFF & TG-ERGHYELALAKADNG \\
\hline$\Gamma \mathrm{PK}$ & GPSWYRYNHDGYGEPAK--------G-------ELYHGKGKGRL----------WPLL & FG-ERGMYEIAAGKKA-- \\
\hline $\mathrm{TPK}$ & GPSWYRYNHDGYGEPSK--------T-------ELYHGAGKGRL----------WPLL & TG-ERGMYEIAAGKDA-- \\
\hline & GPSWYRYNHDGYGEPSK--------T-------ELYHGAGKGRL----------WPLL & TG-ERGMYEIAAGKDA-- \\
\hline & 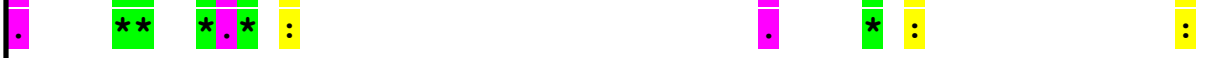 & : $\quad \star \star \star$ \\
\hline
\end{tabular}

\section{$\downarrow \quad$ S5}

GA-A.awamori 386

GA-S.degrad 732

GA-C.subter 639

GA-T.thermo 629

GA-Clostrid 640

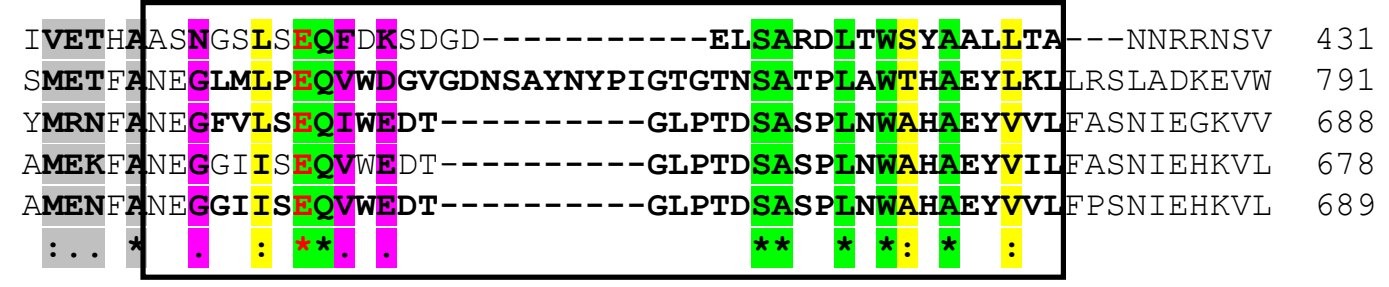




\section{Figure 2}
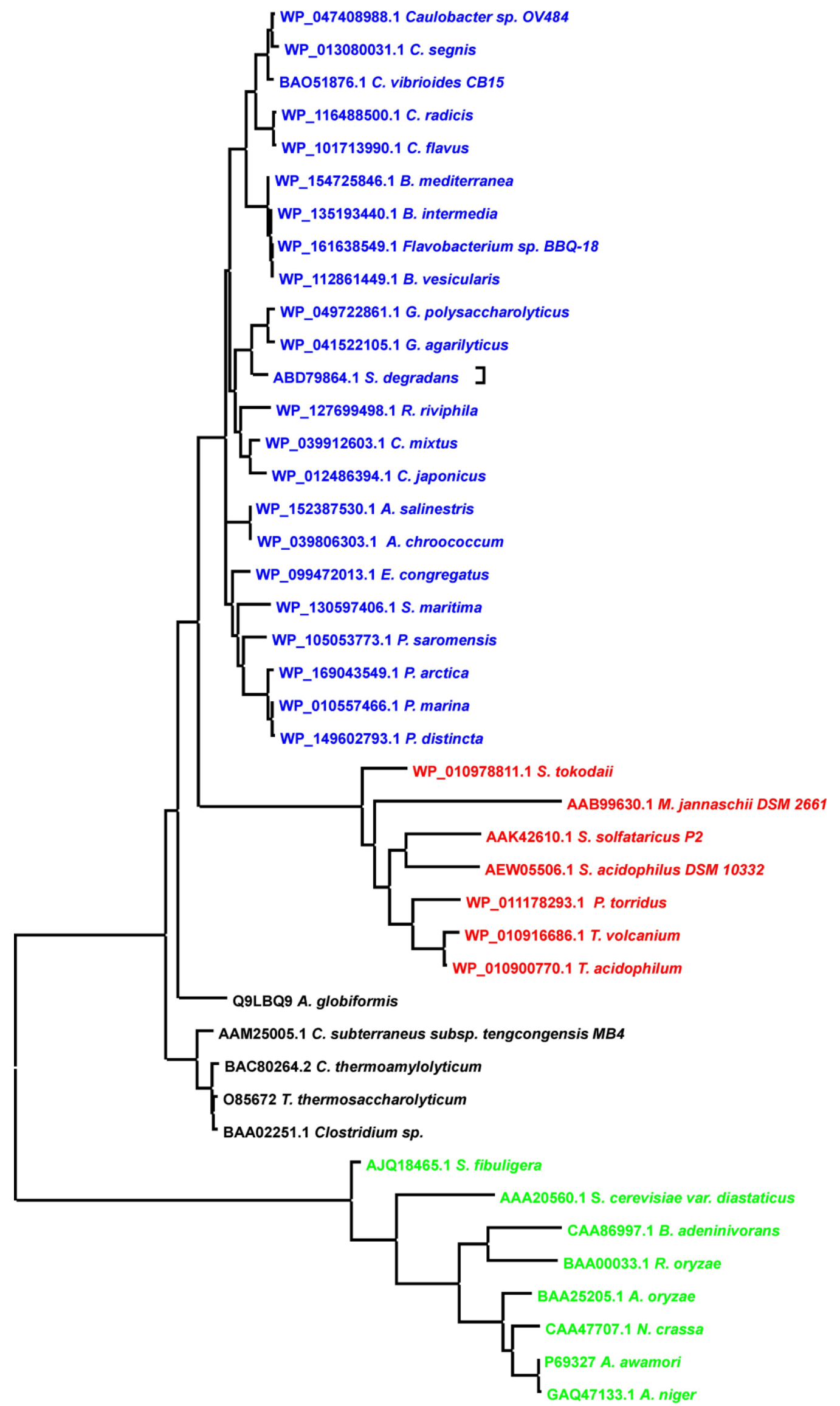


\section{Figure 3}

a

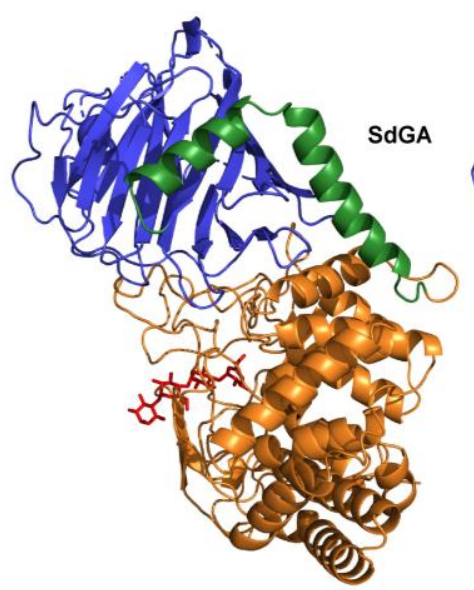

C

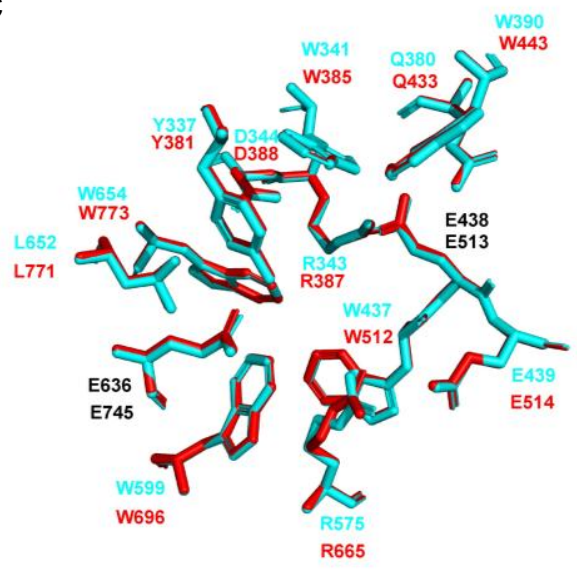

b

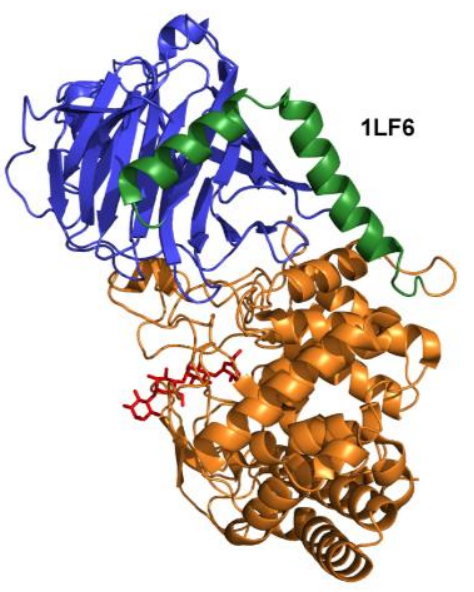

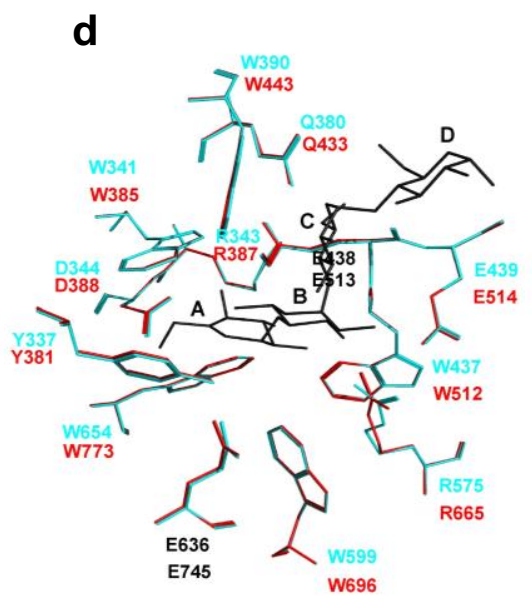




\section{Figure 4}

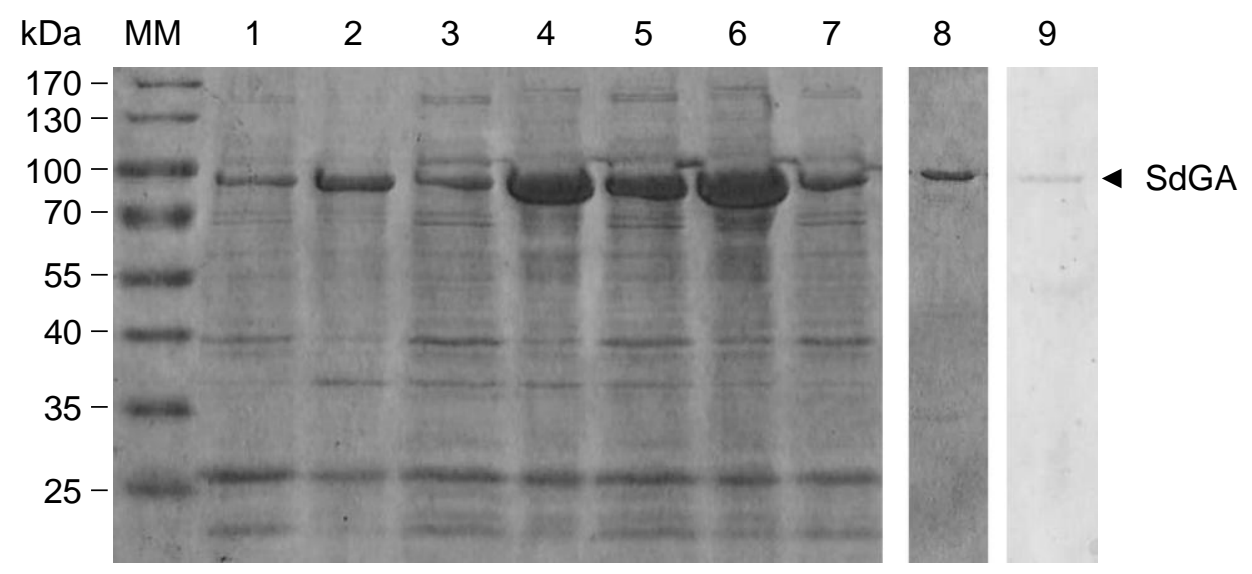




\section{Figure 5}
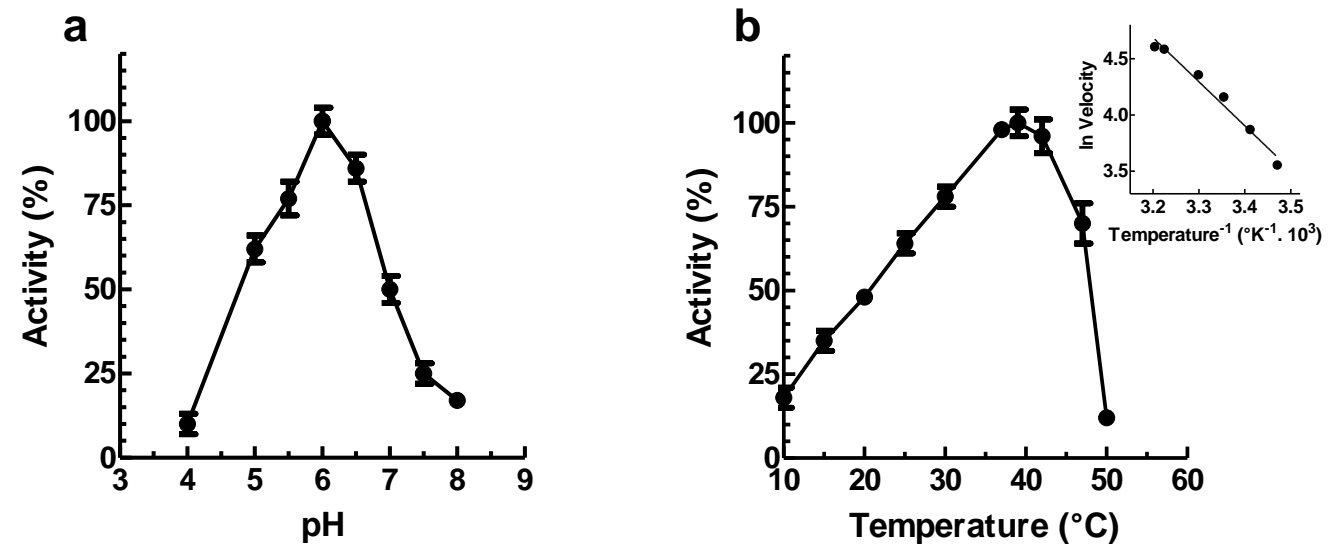


\section{Figure 6}

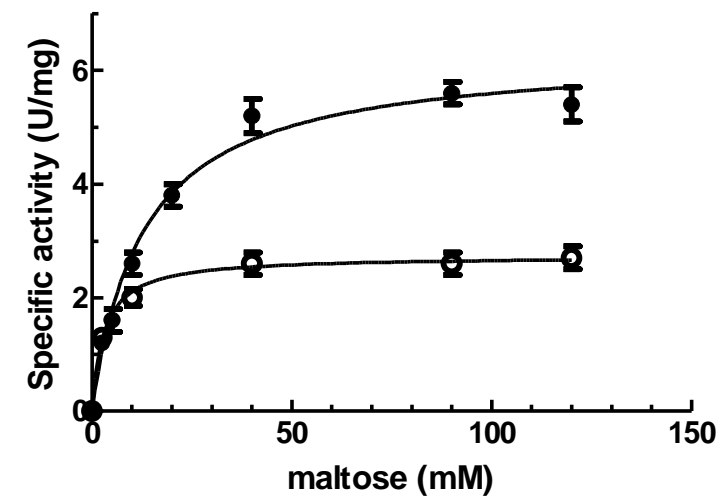




\section{Figure 7}

a

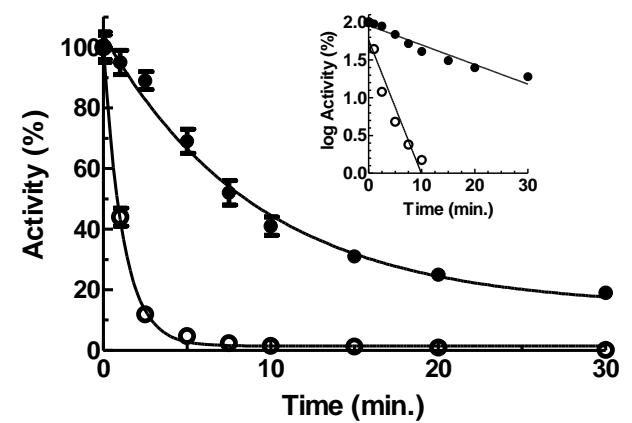

b

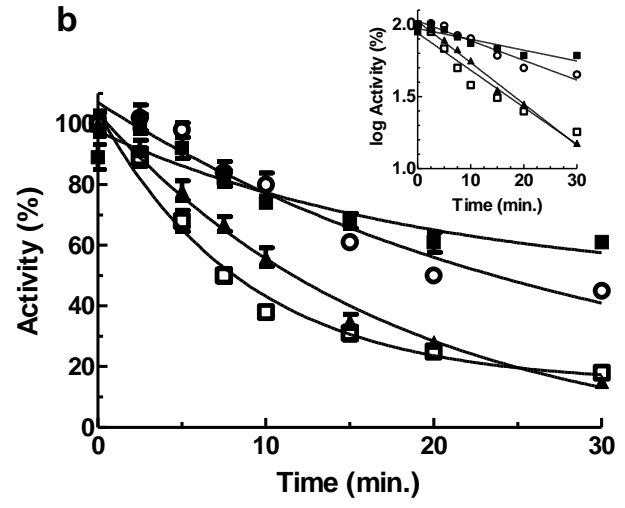

